\title{
ROMANIAN MEN'S HANDBALL VS. THE TOP OF EUROPE MEN'S HANDBALL
}

\author{
Vladi IONESCU ${ }^{1 *}$, Silvia TEODORESCU ${ }^{1}$, Cezar HANTĂU ${ }^{1}$ \\ ${ }^{1}$ National University of Physical Education and Sport, Faculty of Physical Education and Sport, Bucharest, \\ Romania \\ *Corresponding author: vladi_balic@yahoo.com
}

DOI: https://doi.org/10.51267/icpesk2020bp05

\begin{abstract}
This scientific paper proposes a detailed game analysis of the Romanian men's handball team in the European competitions, given that since 1996 it has failed to qualify for any European Championship. As well, since 1995, with the exception of the years 2009 and 2011, it has managed to qualify for no World Championship and, since 1992, it has not qualified for any edition of the Olympic Games. Even if it succeeded to participate in some international competitions, most of the time, Romanian players had a middling performance, being far from the European or world podiums. We have started from the theory that improving team performance involves a deep analysis of the game strategy, the efficiency of technical and tactical combinations used in attack and defence (permanently related to the opposing team's game), and last but not least, each athlete's performance in the competitive game's economy. So, we carried out an analysis of the Romanian men's handball team results within the qualification games for the European Handball Championship 2022, which were played in 2019. We also studied the matches of the teams participating in the 2020 European Handball Championship that played for the 1-12 ranking in Europe. The technical and tactical aspects recorded in each match of each studied team (Romania, Spain, Croatia, Norway, Slovenia, Germany, Portugal, Hungary, Sweden, Iceland, Austria, Belarus, Czech Republic) allowed us to identify the causes, limits and disadvantages of the tactical strategy of our national team.
\end{abstract}

Keywords: men's handball, performance, competition, technical and tactical aspects.

\section{Introduction}

Romania has not achieved sports performance in men's handball for a long time. In this paper, we will compare Romanian men's handball and top European handball according to the characteristics of our national game compared to the game characteristics of the best teams in Europe.

To find out where we are ranked on the European handball scale, we will present a brief history of the performance achieved by each team to which we will refer in this article.

The last great result obtained by our country at an international championship was in 1990, at the World Championship in Czechoslovakia, where we won the bronze medal. Since then, there has been no performance we can be proud of. Our performance level has had a downward trend. Thus, since 1990 until today, we can list only the following results: 10th place out of 16 at the 1993 World Championship, 10th place out of 16 at the 1995 World Championship, 15th place out of 24 at the 2009 World Championship, 19th place out of 24 at the World Championship in 2011, 11th place out of 12 at the 1994 European Championship, 9th place out of 12 at the 1996 European Championship.

Starting with 1990, Spain has had the following results: 1st place at the European and World Championships $(2005,2013,2018,2020)$, 2nd place at the European Championship (1996, 1998, 2006, 2016), 3rd place at the European Championships $(2000,2014)$ and the 2011 World 
Championship, 4th place at the World Championships in 1999, 2015, 2003 and the European Championship in 2012, 5th place at the European and World Championships (1990,1993,1994, 2001, 2017), 6th place at the European Championship in 2010, 7th place at the World Championships $(1997,2007,2019)$ and the European Championship in 2002, 9th place at the European Championship in 2008, 10th place at the European Championship in 2004, 11th place at the World Championship in 1995, 13th place at the World Championship in 2009.

Croatia has had the following results since 1990: 1st place at the World Championship in 2003, 2nd place at the European Championship (2008, 2010, 2020) and the World Championships (1995, 2005, 2009), 3rd place at the European Championships (1994, 2012, 2016) and the World Championship in 2013, 4th place at the European Championships (2004, 2006, 2014) and the World Championship in 2017, 5th place at the European Championships (1996, 2018) and the World Championships (2011, 2007), 6th place at the World Championships $(2015,2019)$ and the European Championships in 2000, 8th place at the European Championship in 1998, 9th place at the World Championship in 2001, 10th place at the World Championship in 1999, 13th place at the World Championship in 1997, 16th place at the European Championship in 2002.

Norway has achieved the following results at the international championships: 2nd place at the World Championships (2017, 2019), 3rd place at the European Championship in 2020, 4th place at the European Championships (2016, 2018), 6th place at the European Championship in 2008, 7th place at the European Championship in 2010 and the World Championship in 2005, 8th place at the European Championship in 2000, 9th place at the World Championships (2009, 2011), 11th place at the European Championship in 2006, 12th place at the World Championship in 1997, 13th place at the World Championships $(1993,1999,2007)$ and the European Championship in 2012, 14th place at the World Championship in 2001 and 14th place at the European Championship in 2014.

Slovenia has had the following results at the international championships: 2nd place at the European Championship in 2004, 3rd place at the World Championship in 2017, 4th place at the World Championship in 2013 and the European Championship in 2020, 5th place at the European Championship in 2000, 6th place at the European Championship in 2012, 8th place at the World Championship in 2015 and the European Championships $(2006,2018)$, 10th place at the 2007 World Championship and the European Championships (1994, 2008), 11th place at the World Championship in 2003 and the European Championships (1996, 2010), 12th place at the World Championship in 2005 and the European Championship in 2002, 14th place at the European Championship in 2016, 17th place at the World Championship in 2001, 18th place at the World Championship in 1995.

Germany has recorded the following results: 1st place at the World Championship in 2007 and the European Championships (2004, 2016), 2nd place at the World Championship in 2003 and the European Championship in 2002, 3rd place at the European Championship in 1998, 4th place at the World Championships $(1995,2019)$ and the European Championship in 2008, 5th place at the World Championships $(1999,2009,2013)$ and the European Championships (2006, 2020), 6th place at the World Championship in 1993, 7th place at the World Championship in 2015 and the European Championship in 2012, 8th place at the World Championship in 2001 and the European Championship in 1996, 9th place at the World 
Championships $(2005,2017)$ and the European Championships (1994, 2000, 2018), 10th place at the European Championship in 2010, 11th place at the World Championships in 2010, 2011.

Portugal has achieved the following results: 6th place at the European Championship in 2020, 7th place at the European Championship in 2000, 9th place at the European Championship in 2002, 12th place at the World Championship in 2003 and the European Championship in 1994, 14th place at the European Championship in 2004, 15th place at the European Championship in 2006, 16th place at the World Championship in 2001, 19th place at the World Championship in 1997.

Sweden has ranked at the international championships as follows: 1st place at the World Championships (1990, 1999) and European Championships (1994, 1998, 2000, 2002), 2nd place at the World Championships $(1997,2001)$ and the European Championship in 2018, 3rd place at the World Championships (1993, 1995), 4th place at the World Championship in 2011 and the European Championship in 1996, 5th place at the World Championship in 2019 and the European Championship in 2008, 6th place at the World Championship in 2017, 7th place at the World Championship in 2009 and the European Championships in 2004, 2014, 2020, 8th place at the European Championship in 2016, 10th place at the World Championship in 2015, 11th place at the World Championship in 2005, 12th place at the European Championship in 2012, 13th place at the World Championship in 2003, 15th place at the European Championship in 2010.

Austria has the following records: 8th place at the European Championship in 2020, 9th place at the European Championship in 2010, 11th place at the European Championship in 2014, 13th place at the World Championship in 2015, 14th place at the World Championship in 1993, 15th place at the European Championship in 2018, 18th place at the World Championship in 2011, 19th place at the World Championship in 2019.

Hungary has the following records: 4th place at the World Championships in 1997, 6th place at the World Championships (1990, 2003, 2009) and the European Championship in 1998, 7th place at the World Championships in 2011, 2017 and the European Championship in 1994, 8th place at the World Championship in 2013 and the European Championships (2008, 2012, 2014), 9th place at the World Championship in 2007 and the European Championships (2004, 2020), 10th place at the World Championship in 2019 and the European Championship in 1996, 11th place at the World Championships (1993, 1999), 12th place at the European Championship in 2016, 13th place at the European Championship in 2006, 14th place at the European Championships (2010, 2018), 17th place at the World Championship in 1995.

Belarus has the following records: 8th place at the European Championship in 1994, 9th place at the World Championship in 1995, 10th place at the European Championships (2016, 2018, 2020), 11th place at the World Championship in 2017, 12th place at the European Championship in 2014, 15th place in the World Championship in 2013 and the European Championship in 2008, 18th place in the World Championship in 2015.

Iceland has the following records: 3rd place at the European Championship in 2010, 4th place at the European Championship in 2002, 5th place at the World Championship in 1997 and the European Championship in 2014, 6th place at the World Championship in 2011, 7th place at the World Championship in 2003 and the European Championship in 2006, 8th place at the World Championships (1993, 2007), 10th place at the World Championship in 1990 and the European Championship in 2012, 11th place at the World Championships (2001, 2015, 
2019) and European Championships (2000, 2008, 2020), 12th place at the World Championship in 2013, 13th place at the European Championships $(2004,2016,2018), 14$ th place at the World Championships (1995, 2017), 15th place at the 2005 World Championship.

The Czech Republic has the following records: 6th place at the European Championships (1996, 2018), 7th place at the World Championships (1990 - Czechoslovakia, 1993 Czechoslovakia), 8th place at the World Championship in 1995 and the European Championships (2002, 2010), 10th place at the World Championship in 2005 and the European Championship in 1998, 11th place at the World Championship in 1997 and the European Championship in 2004, 12th place at the World Championship in 2007 and the European Championship in 2020, 13th place at the European Championship in 2008, 14th place at the European Championship in 2012, 15th place at the European Championship in 2014, 17th place at the World Championship in 2015, 18th place at the World Championship in 2001.

If we made a comparison of Romania's results obtained over time with those of the other teams mentioned, we would conclude that it is natural where we are now in terms of performance. Most of the above teams have a large number of entries and places at the top of the rankings for the World and European Championships. Only one team can be considered excluded from this pattern, and that is Portugal.

However, these remarkable results are only achieved through a harmonious combination of several elements that influence performance. Among them, we can mention the training of athletes, be it physical, technical/tactical, psychological, theoretical, handball management at national level, economy, and financial resources representative of handball activity in the country, tradition, infrastructure, material and human resources, etc. Regarding these decisive factors for performance, we will express some opinions of a number of specialists.

In general, for sports games and especially the game of handball, physical training is the basis for other factors of sports training (technical, tactical, psychological training, etc.). In the annual training cycle, specific physical training is present in all stages and periods of training, but with a different weight. Its optimisation is achieved after proper general physical training developed in the first years of handball, but also at the beginning of each annual training. (Mihăilă, 2016)

The training period before the start of the season, the pre-competitive stage, is the one meant to promote an increase in physical performance (Milanez et al., 2014).

In handball, at all levels of performance, physical training marks the entire training process, with an influence on the efficiency of athletes in training and competitions. In sports games, especially in the game of handball, physical training has a decisive importance in the training of children and juniors by stimulating major body functions, which help to adapt the body to the sport-specific demands.

The main goal of general physical training is to develop basic and combined motor skills so that athletes do not encounter difficulties in solving higher-level actions in the game of handball (Mihăilă, 2015).

Technical training is also present at all levels of performance. If properly performed, it becomes possible to optimally use the opportunities that arise in the game, and players can solve tactical situations in conditions of adversity and energy saving (Mihăilă, 2014).

In order to successfully use the defensive formation, the relations between players require compliance with certain operating rules, such as marking the opponent with the ball, stopping 
movements behind the defenders, crowding the area where the ball is, mutual aid, dividing roles in organizing the relation of players within the team (translational movement, alignment, division of people in defence, sliding) (Bayer, 1993, cited in Prisăcaru, 2015).

High-performance sports activity is considered to be an activity at the limit of human capabilities. It is conditioned by the physical and mental development of the athlete.

Nowadays, all stages of sports training require the contribution of psychology. Experts in the field state that psychology has a defining contribution to optimising sports performance (Cicma \& Mereuța, 2013).

Sports performance can only be achieved by implementing high-performance management that involves highly qualified specialists as well as material, human, financial and information resources to support successful participation in major competitions (Mihăilă, 2018).

According to specialised articles, a series of trends can be noticed in the handball game at the level of juniors and youth (Romila \& Macovei, 2018). Statistical analyses of the European Handball Championships for national youth teams tell us the following:

- The teams that participated in the 2016 European Championship mainly used the $5+1$ or 6: 0 defence formation.

- In the attack phase, all teams started with the "horseshoe" formation, but most of them used the two-pivot attack formation during the game. In most cases, the wings that went into circulation on the semicircle turned into the second pivot, but it also happened in the case of the left or right back or the centre back.

- Regarding the use of the technique, a tendency towards bilateral development can be observed, this being used on both sides of the body.

- According to statistical analyses, handball schools that have achieved good results over time manage to maintain the same standards, even if there are other generations of players. Young players manage to complement the generation of senior players. It has been noted that, in recent years, teams from France, Germany, Denmark and Spain have achieved good results in both seniors and juniors.

In order to detach the main characteristics and trends in men's world handball, we analysed in this paper 64 official matches played by the 13 national teams in the 2020 European Championship, but also the qualifications for the 2022 European Championship.

On the other hand, we analysed the tactical strategy of the Romanian men's national handball team trying to detect its neuralgic points, possible causes and/or limits.

\section{Purpose of study}

The aim of the paper is to identify the causes leading to the low performance of the national men's handball team and to outline some directions in the preparation of future generations by eliminating these negative aspects.

After analysing Romania's qualifying games for the European Championship 2022, we summarised all the data and obtained information about the following: throws made on the counterattack, in the second phase, in the positional attack (in all positions), number and type of formations and systems used in attack and defence, goals conceded with an empty net, number of eliminations received, interceptions made, number of regulatory and passing errors, average number and efficiency of positional attacks complemented by the tactical scheme and 
individual action, percentage of balls blocked by the goalkeeper, efficiency of penalty shots from $7 \mathrm{~m}$ and effectiveness of positional attacks (Table 1).

Using the observation method, we can say that the mediocre performance of Romania's game is mainly due to the increased number of regulatory and passing errors, low efficiency of the counterattack, second phase and positional attack, low number of attack formations used, increased number of goals conceded on the opponent's positional attack. Other causes can also be represented by the other elements analysed.

Table 1. Summarised data of the Romanian men's national handball team

\begin{tabular}{|c|c|c|c|c|c|c|c|c|}
\hline \multirow{2}{*}{$\begin{array}{l}\text { Average number } \\
\text { of throws on the } \\
\text { counterattack }\end{array}$} & \multirow{2}{*}{$\begin{array}{l}\text { Average number } \\
\text { of throws in the } \\
\text { second phase of } \\
\text { the attack }\end{array}$} & \multirow{2}{*}{$\begin{array}{l}\text { Average number } \\
\text { of throws in the } \\
\text { positional attack }\end{array}$} & \multicolumn{6}{|c|}{ Average number of throws in the positional attack } \\
\hline & & & $\begin{array}{l}\text { From left } \\
\text { wing }\end{array}$ & $\begin{array}{c}\text { From } \\
\text { left } \\
\text { back }\end{array}$ & $\begin{array}{l}\text { From } \\
\text { centre } \\
\text { back }\end{array}$ & $\begin{array}{c}\text { From } \\
\text { right back }\end{array}$ & $\begin{array}{l}\text { From } \\
\text { right wing }\end{array}$ & $\begin{array}{l}\text { From } \\
\text { pivot }\end{array}$ \\
\hline 2.5 & 5 & 30.5 & 1.3 & 7 & 5.3 & 9.5 & $2 / 6$ & 5 \\
\hline \multirow{2}{*}{$\begin{array}{l}\text { Counterattacking } \\
\text { efficiency }\end{array}$} & Efficiency of & Efficiency of & \multicolumn{6}{|c|}{ Efficiency of throws in the positional attack } \\
\hline & $\begin{array}{l}\text { throws in the } \\
\text { second phase of } \\
\text { the attack }\end{array}$ & $\begin{array}{l}\text { throws in the } \\
\text { positional attack }\end{array}$ & $\begin{array}{l}\text { From left } \\
\text { wing }\end{array}$ & $\begin{array}{c}\text { From } \\
\text { left } \\
\text { back }\end{array}$ & $\begin{array}{l}\text { From } \\
\text { centre } \\
\text { back }\end{array}$ & $\begin{array}{l}\text { From } \\
\text { right back }\end{array}$ & $\begin{array}{l}\text { From } \\
\text { right wing }\end{array}$ & $\begin{array}{l}\text { From } \\
\text { pivot }\end{array}$ \\
\hline $80 \%$ & $56 \%$ & $53.5 \%$ & $62.5 \%$ & $32.5 \%$ & $62.5 \%$ & $47.3 \%$ & $56.25 \%$ & $86.6 \%$ \\
\hline $\begin{array}{l}\text { Predominantly } \\
\text { used attack } \\
\text { formation }\end{array}$ & $\begin{array}{l}\text { Average number } \\
\text { of attack } \\
\text { formations used }\end{array}$ & $\begin{array}{l}\text { Predominantly } \\
\text { used type of } \\
\text { defence system }\end{array}$ & $\begin{array}{l}\text { Predominantly } \\
\text { used defence } \\
\text { formation }\end{array}$ & \multicolumn{5}{|c|}{ Average number of defence formations used } \\
\hline $\begin{array}{c}\text { Horseshoe (6 } \\
\text { people in attack } \\
\text { with man } \\
\text { eliminated) }\end{array}$ & 1 & In the area & 6-0 & \multicolumn{5}{|c|}{1.5} \\
\hline $\begin{array}{l}\text { Average number } \\
\text { of goals conceded } \\
\text { with an empty net }\end{array}$ & $\begin{array}{c}\text { Average number } \\
\text { of eliminations } \\
\text { received }\end{array}$ & $\begin{array}{l}\text { Average number } \\
\text { of interceptions }\end{array}$ & $\begin{array}{l}\text { Average } \\
\text { number of } \\
\text { regulatory } \\
\text { errors }\end{array}$ & \multicolumn{5}{|c|}{ Average number of passing errors } \\
\hline 0.66 & 3.5 & 1.83 & 5.3 & & & 7 & & \\
\hline $\begin{array}{l}\text { Average number } \\
\text { of completed } \\
\text { positional attacks - } \\
\text { tactical scheme }\end{array}$ & $\begin{array}{l}\text { Average number } \\
\text { of completed } \\
\text { positional attacks } \\
\text { - individual } \\
\text { action }\end{array}$ & $\begin{array}{c}\text { Efficiency of } \\
\text { completed } \\
\text { positional attacks } \\
\text { - tactical scheme }\end{array}$ & $\begin{array}{l}\text { Efficiency of } \\
\text { completed } \\
\text { positional } \\
\text { attacks - } \\
\text { individual } \\
\text { action }\end{array}$ & $\begin{array}{r}\text { Efficie } \\
\text { balls bl } \\
\text { by t } \\
\text { goalke }\end{array}$ & & $\begin{array}{l}\text { Efficiency of } \\
\text { throws from } 7 \\
\text { m }\end{array}$ & \multicolumn{2}{|c|}{$\begin{array}{l}\text { Efficiency of positional } \\
\text { attacks (+ errors) }\end{array}$} \\
\hline 5.5 & 25.5 & $54.54 \%$ & $54.24 \%$ & 39 & & $82.35 \%$ & \multicolumn{2}{|c|}{$38.84 \%$} \\
\hline
\end{tabular}

\section{Research hypotheses}

Hypothesis 1 - Romania has low attack efficiency because it commits more regulatory and passing errors than the teams ranked 1-6 and 7-12 in Europe.

Hypothesis 2 - Romania barely manages to score in the positional attack because it does not use enough tactical schemes.

With the help of this research in which we compare the data obtained by Romania and the other top handball teams, we will answer the following questions:

1. What are some of the main causes of the poor game played by the Romanian men's national handball team?

2. What are the factors that determine these causes?

The test results will confirm or reject the hypotheses and will answer our questions.

\section{Methodology}

During the research, 3 samples consisting of 6 handball teams were made up as follows: the "Romania" sample, the "1-6 Europe" sample (represented by the teams ranked 1-6 at the last 
European Men's Handball Championship) and the "7-12 Europe" sample (represented by the teams ranked 7-12 at the same championship). The "1-6 Europe" sample includes handball teams from Spain, Croatia, Norway, Slovenia, Germany and Portugal, while the "7-12 Europe" sample includes handball teams from Sweden, Hungary, Iceland, Belarus, Austria and Czech Republic. The "Romania" sample is of course represented by Romania.

The variables of each sample are the games played by each team in that group. Thus, for the "Romania" group, we analysed 6 official games, for the "1-6 Europe" group, 34 matches, and for the "7-12 Europe" group, 24 matches. The difference between the number of subjects in each sample is influenced by both the number of representative teams and the phase in which they entered the competition. Therefore, the teams that reached the semi-finals, finals, little finals and the match for places 5-6 played one or two more matches than the other teams.

As materials used, we can describe the registration sheet to collect data from each game played. We will present below a model of such a file (Tables 2 and 3):

Table 2. Game sheet for recording matches at the European Handball Championship (I)

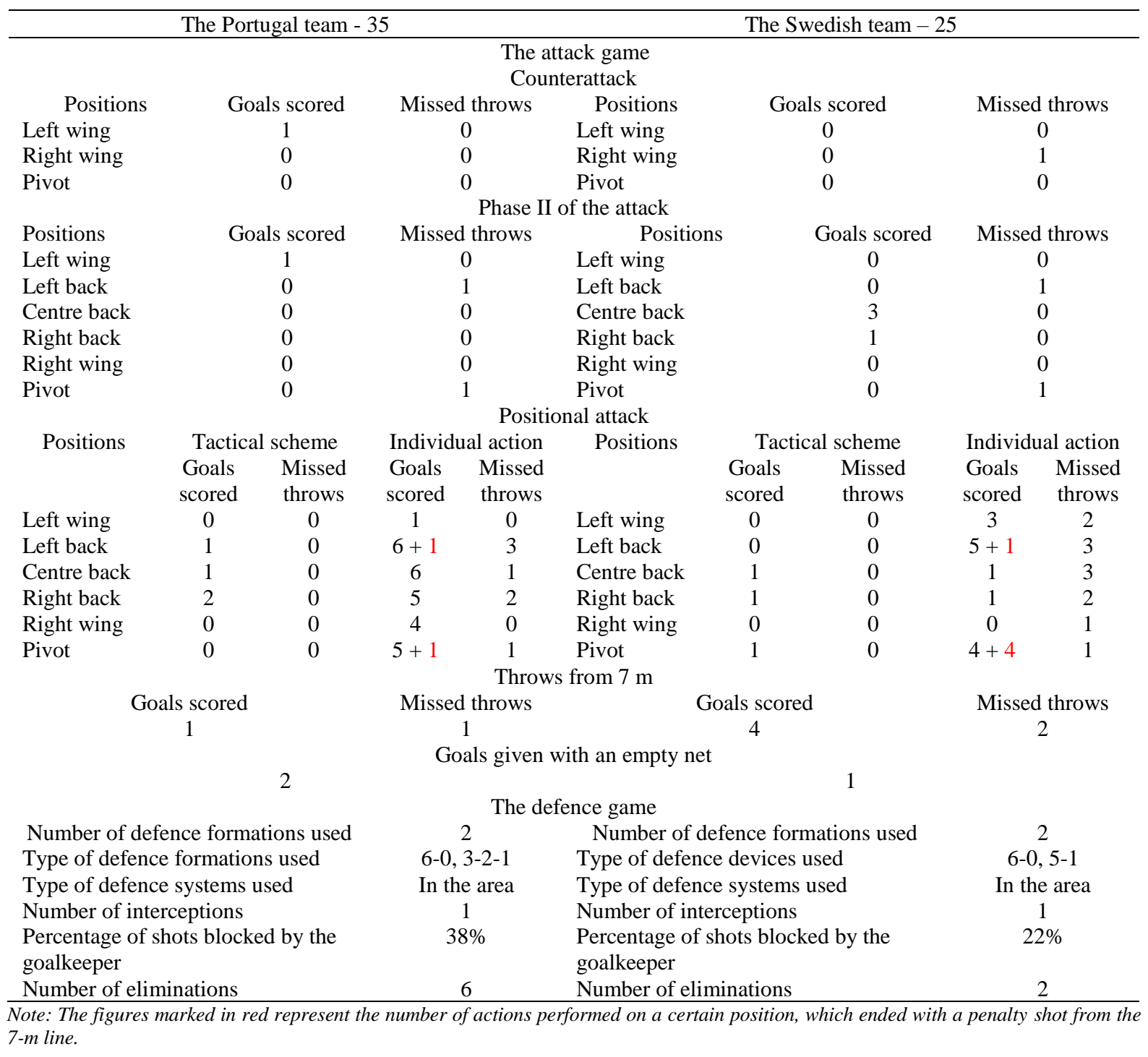


Table 3. Game sheet for recording matches at the European Handball Championship (II)

\begin{tabular}{|c|c|}
\hline The Portugal team & The Swedish team \\
\hline \multicolumn{2}{|c|}{ Predominantly used formation in defence } \\
\hline $6-0$ & $6-0$ \\
\hline \multicolumn{2}{|c|}{ Other aspects } \\
\hline \multicolumn{2}{|c|}{ Game errors } \\
\hline 6 & 5 \\
\hline \multicolumn{2}{|c|}{ Regulatory errors } \\
\hline 3 & 4 \\
\hline \multicolumn{2}{|c|}{ Number of passes } \\
\hline 869 & 699 \\
\hline \multicolumn{2}{|c|}{ Distance run by the team } \\
\hline \multirow{2}{*}{\multicolumn{2}{|c|}{ Formation used in attack }} \\
\hline & \\
\hline \multicolumn{2}{|c|}{$\begin{array}{l}\text { Horseshoe, } 6 \text { people on the field (with man eliminated), } 7 \quad \text { Horseshoe, } 6 \text { people on the field (with man eliminated) } \\
\text { people in attack }\end{array}$} \\
\hline \multicolumn{2}{|c|}{ Predominantly used formation in attack } \\
\hline
\end{tabular}

During the research, we had to choose a test to determine whether the differences between Romania's data and those of the other samples were significant. Because there were 3 samples, the number of subjects was different in each sample and, as we wanted to compare the data of one group with the other two groups, we chose the ANOVA test. The test was analysed using the Prism 8 GraphPad program.

The ANOVA test provides us with information on the statistical significance of the difference between uncorrelated sample averages (the p-value - 95\% Confidence Interval - CI) and, respectively, the confirmation or rejection of the research hypotheses.

\section{Results}

a. Hypothesis 1 - Romania has low attack efficiency because it commits more regulatory and passing errors than the teams ranked 1-6 and 7-12 in Europe.

To verify this hypothesis, we created a table where we noted the number of errors made by each team in each match played (Table 4). As we said before, the teams represent the samples, and the matches represent the subjects.

Table 4. Interpretation of statistical data by the ANOVA test

\begin{tabular}{lcccccc}
\hline \multicolumn{1}{c}{ Test details } & Mean 1 & Mean 2 & Mean diff. & 95\% CI of diff. & Adjusted p-value & Significant? \\
\hline Romania vs. 7-12 Europe & 12.33 & 8.667 & 3.667 & 0.9151 to 6.418 & 0.0081 & Yes \\
Romania vs. 1-6 Europe & 12.33 & 7.971 & 4.363 & 1.693 to 7.032 & 0.0012 & Yes \\
\hline
\end{tabular}

After analysing these data (according to the ANOVA test), we highlight the arithmetic average of the number of errors made by each handball team. Thus, we can observe that Romania commits on average 12.33 regulatory or passing errors per match compared to the "712 Europe" group that commits only 8.667 errors on average and the "1-6 Europe" group that commits on average 7.971 errors per match. The error difference between Romania and the teams ranked 7-12 in Europe is 3.667, and that between Romania and the teams ranked 1-6 in Europe is 4.363 . 
The ANOVA test tells us that, if $\mathrm{p}$ is less than $\alpha(\mathrm{alpha}=0.05)$, then the difference in value is statistically significant. The p-value, when comparing Romania with the teams ranked 7-12 in Europe, is 0.0081, and when comparing Romania with the teams ranked 1-6 in Europe, is 0.0012 .

It turns out that the difference is statistically significant and confirms the hypothesis when comparing Romania with both the first half and the second half of the European elite, so "Romania has low attack efficiency because it commits more regulatory and passing errors than the teams ranked 1-6 and 7-12 in Europe".

b. Hypothesis 2 - Romania barely manages to score in the positional attack because it does not use enough tactical schemes.

To verify this hypothesis, we created a table where we noted the number of attacks of each team in each match played, the attacks being complemented by the tactical scheme (Table 5). As we said before, the teams represent the samples, and the matches represent the subjects.

Table 5. Interpretation of statistical data by the ANOVA test

\begin{tabular}{lcccccc}
\hline \multicolumn{1}{c}{ Test details } & Mean 1 & Mean 2 & Mean diff. & 95\% CI of diff. & Adjusted p-value & Significant? \\
\hline Romania vs. 7-12 Europe & 5.333 & 7.292 & -1.958 & -5.940 to 2.024 & 0.3911 & No \\
Romania vs. 1-6 Europe & 5.333 & 6.500 & -1.167 & -5.030 to 2.696 & 0.6609 & No \\
\hline
\end{tabular}

After analysing these data (according to the ANOVA test), we can say that the arithmetic average is meant to provide information about the attacks complemented by the tactical scheme of each handball team. Thus, we can observe that Romania has an average of 5.333 such attacks compared to the "7-12 Europe" group, with an average of 7.292 attacks complemented by the tactical scheme, and the "1-6 Europe" group, with an average of 6.500 attacks per match performed using the tactical scheme. The difference in the average number of attacks between Romania and the teams ranked 7-12 in Europe is 1.958, and that between Romania and the teams ranked 1-6 in Europe is 1.167.

According to the ANOVA test, if $\mathrm{p}$ is less than $\alpha$ (alpha $=0.05$ ), then the difference in value is statistically significant. The p-value, when comparing Romania with the teams ranked 7-12 in Europe, is 0.3911, and when comparing Romania with the teams ranked 1-6 in Europe, is 0.6609 .

It turns out that the difference between the number of attacks performed by Romania compared to the teams in the first half and the second half of the European elite is statistically insignificant, which rejects the research hypothesis and, as a result, the reason why Romania barely manages to score in the positional attack is not due to the use of a low number of tactical schemes.

\section{Conclusion}


The results of the research show that Romania has low attack efficiency because it commits more regulatory and passing errors than the teams ranked 1-6 and 7-12 in Europe, and the low number of tactical schemes used in the attack does not influence its success.

So, we can conclude that the collective tactical strategy is not as important as the individual tactics, which must be mastered perfectly at this level. Moreover, the execution of technical procedures must be done with great skill, in the sense of adapting it to each game situation. Without the proper use of technical elements and procedures, players will not be able to successfully perform individual tactical actions. Without successfully performing individual tactics, we cannot have high expectations for team tactics.

The use of individual attack and defence tactics produces high game efficiency and effectiveness in the application of collective tactics. In the current game conditions, one can observe the tendency to give controlled freedom to the defender in performing individual actions, following the established tactical plan. (Balint, 2013)

Our conclusions are supported by other specialists who report that, in the modern game, the attack is carried out by applying technical procedures acquired through tactical actions between two or three players (Romila \& Macovei, 2018). Collective tactical combinations become less used. The emphasis is on the fast circulation of the ball by attacking the lanes and finding solutions from optimal positions that can be completed by scoring a goal.

The above authors (Romila \& Macovei, 2018) also focus on the management of handball activity for children and juniors. They state that a national team has valuable players due to the efficient work at junior level and that, in order to raise valuable players at senior level, a wellprepared training strategy for juniors should be considered.

Several specialists propose in their studies the extension of the training period for children and junior handball players with another four-year cycle. This change ensures a decrease in the age of contact with organized handball training. (Hantău et al., 2013)

The results obtained in this research lead us to the conclusion that, in order to achieve performance in men's handball at national level, the training of athletes should be focused on physical, technical and tactical training, especially on improving technical performance and individual tactics, as well as on psychological training.

\section{Authors' Contributions}

All authors have equally contributed to this study and should be considered as main authors.

\section{References}

Balint, E. (2013). The importance of anticipation in increasing the defense efficiency in high performance handball. Procedia - Social and Behavioral Sciences, 76, 77-83. https://doi.org/10.1016/j.sbspro.2013.04.077

Cicma, I. T., \& Mereuța, C. (2013). The importance of the psychological training in increasing the performance in handball. Procedia - Social and Behavioral Sciences, 84, 1350-1355. https://doi.org/10.1016/j.sbspro.2013.06.755

Hantău, C., Nae, C., Hantău, C., \& Neagu, N. (2013). Formation strategy for the young handball players. Procedia - Social and Behavioral Sciences, 93, 1936-1939.

https://doi.org/10.1016/j.sbspro.2013.10.144 
Mihăilă, I. (2018). The organization and management of sports teams in competitions. The European Proceedings of Social \& Behavioural Sciences, 67, 1202-1206. https://doi.org/10.15405/epsbs.2019.08.03.147

Mihăilă, I. (2016). Experimentation exercises to achieve specific physical preparation handball teams to performance. The European Proceedings of Social \& Behavioural Sciences, 23, 1756-1762. http://dx.doi.org/10.15405/epsbs.2017.05.02.215

Mihăilă, I. (2015). Ways to optimize the general physical training at the junior handball teams. Procedia - Social and Behavioral Sciences, 180, 1263-1268. https://doi.org/10.1016/j.sbspro.2015.02.262

Mihăilă, I. (2014). Technical training methods for increasing the junior handball teams. Procedia - Social and Behavioral Sciences, 116, 2004-2009. https://doi.org/10.1016/j.sbspro.2014.01.511

Milanez, V. F., Ramos, S. P., Lepretre, P. M., Leme, L. C., \& Nakamura, F. Y. (2014). Physiological and performance changes in response to pre-season training in high level handball players. Science \& Sports, 29(4), e59-e62. https://doi.org/10.1016/j.scispo.2014.03.003

Prisăcaru, I. R. (2015). Tactical action rules for nearly marking and for closing the penetration of the direct opponent in possession of the ball. The European Proceedings of Social \& Behavioural Sciences, 11, 46-53. http://dx.doi.org/10.15405/epsbs.2016.06.7

Romila, C., \& Macovei, S. (2018). Comparative analysis of tactical models in juvenile handball in countries of Europe. The European Proceedings of Social \& Behavioural Sciences, 55, 533-542. https://dx.doi.org/10.15405/epsbs.2019.02.67 